\title{
Effect of Cold Work on Cavitation Resistance of an Austenitic Stainless Steel Coating
}

\author{
Juliane Ribeiro da Cruz $z^{a}$, Sérgio Luiz Henke , Ana Sofia Clímaco Monteiro d'Oliveira ${ }^{a, b *}$ \\ ${ }^{a}$ Post graduate program in Materials Science and Engineering, Universidade Federal do Paraná- \\ UFPR, Centro Politécnico, CEP 81531-990, Curitiba, PR, Brazil \\ ${ }^{b}$ Mechanical Engineering Department, Universidade Federal do Paraná - UFPR, Centro Politécnico, \\ CEP 81531-990, Curitiba, PR, Brazil
}

Received: August 3, 2015; Revised: December 13, 2015; Accepted: July 13, 2016

\begin{abstract}
Machining procedures of welding deposits are usual and result on cold work hardened surfaces. The cold work effect on cavitation erosion of an austenitic stainless steel surface is assessed. $\mathrm{FeCrMnSiB}$ coatings were processed by PTA on AISI 304 plates. Specimens were grouped as the cold work deformed surface (CWHS) and the undeformed polished surface (UPS) specimens. Top surface and transverse section of coatings were analysed for slip lines and hardness changes by light microscopy and Vickers microhardness measurements. Ultrasonic cavitation tests were conducted in accordance to ASTM G32-10. CWHS specimens exhibited slip lines and hardened surfaces while UPS specimens did not show traces of slip lines and had insignificant changes on microhardness. Cold work prior to cavitation indirectly increased the nominal incubation time and reduced the maximum erosion rate. Cold work increases the duration of the acceleration period postponing the onset of the maximum erosion rate and enhancing cavitation resistance.
\end{abstract}

Keywords: Cold work deformation, Plastic deformation, Cold work hardening, Cavitation erosion, Acceleration period, Nominal incubation time, Incubation period, $\mathrm{Fe}-\mathrm{Cr}$-Mn-Si austenitic stainless steel

\section{Introduction}

The surface of hydraulic machinery is often eroded by a mechanism named cavitation. Cavitation erosion occurs when bubbles form in the liquid in regions where the absolute pressure is below its vapor pressure. Under these conditions bubbles collapse violently generating water jets and shock waves against the surface of parts ${ }^{1}$. Hydraulic components can be manufactured with carbon steel, austenitic and martensitic stainless steels (such as AISI 304 and ASTM A743 CA6NM ${ }^{2-4}$ or even cast iron ${ }^{5,6}$. Parts are often coated with cavitation resistant materials in order to enhance service life or as a consequence of a repair procedure.

Cavitation erosion behavior of materials is often represented by the characteristic curves of cumulative mass loss (Figure 1a) and erosion rate (Figure 1b) versus cavitation exposure time. According to the ASTM G32-10 standard, data distribution allows to identify the three stages of cavitation erosion, i. e., incubation period, acceleration period and maximum-rate period. Notwithstanding, the boundaries of each stage can be diffuse, as perceived by the incubation period definition in the mentioned standard (the period in which the erosion rate is zero or negligible compared to other stages, A in Figure $1 \mathrm{a}$ and $1 \mathrm{~b}$ ), that leaves room for a subjective interpretation.

The cavitation resistance of a material is frequently characterized by the incubation period and maximum erosion rate $^{7,9-13}$. Another less subjective parameter used to measure

*e-mail: sofmat@ufpr.br the initial period of cavitation and required in technical reports by ASTM G32-10, is the nominal incubation time (determined by the interception between the cavitation time axis and the extension of the maximum erosion rate line fitting, B in Figure 1a and 1b).

The incubation stage is of particular importance in low stacking fault alloys, such as MnSi and Co alloyed austenitic stainless steels. These alloys accommodate the impact of shock waves creating stacking faults and extending the incubation period ${ }^{8-10,14,15}$. In other metallic alloys, strain hardening during cavitation also plays an important role as a mechanism partially responsible for the magnitude of the incubation period ${ }^{16}$. Therefore, the ability of the alloy to accommodate plastic deformation can be associated with an enhanced cavitation resistance. That leads to the hypothesis that machined surfaces that undergo cold work deformation may have a detrimental effect on cavitation resistance, as a high dislocation density can be found on the surface, compromising the ability to accommodate further plastic deformation. However, literature shows that stainless steels with a cold worked surface exhibit an improved cavitation erosion resistance, associated with both an increase on the nominal incubation time and the reduction on the erosion rate $^{11,12}$. Such improvement is attributed to an increase in hardness and resistance to plastic deformation ${ }^{11}$. The formation of a $\left\{\begin{array}{lll}1 & 0 & 1\end{array}\right\} / /$ surface texture under cold-work may also increase the cavitation erosion ${ }^{11}$. The understanding of this apparent contradiction between the expected effect of cold 

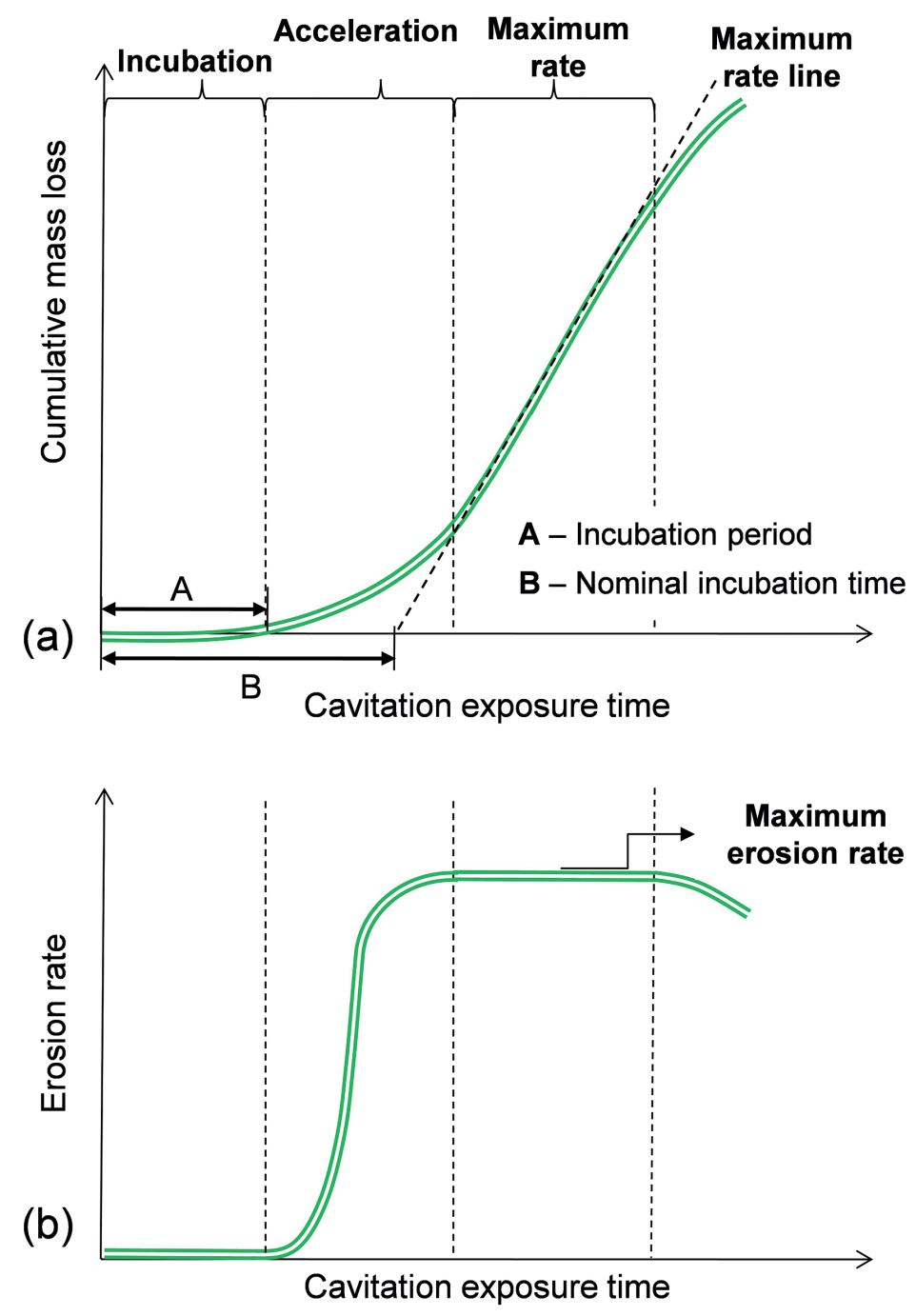

Figure 1: Characteristic curves of cumulative mass loss and erosion rate vs. cavitation exposure time. The three initial stages of cavitation are identified: incubation period, acceleration period and maximum rate period. Nominal incubation time is also indicated

work deformation on cavitation resistance and experimental findings is highly significant since surfaces of hydraulic equipment are machined before exposure to cavitation erosion susceptible environments.

This study aims to assess the effect of cold work deformed structures on the cavitation resistance of a FeCrMnSiB austenitic stainless steel coating and to contribute to the discussion on the effect of deformed structures on the cavitation erosion behavior.

\section{Experimental procedures}

Coatings were processed on $102 \times 50 \times 13 \mathrm{~mm}$ plates of AISI 304 stainless steel by Plasma Transferred Arc with the parameters listed on Table 1. A non-commercial FeCrMnSiB austenitic stainless steel (patent pending) was deposited. One layer composed of eight overlapping beads was produced. Before removing specimens for cavitation erosion tests, face milling was carried out at the top and bottom surfaces to guarantee parallelism.

Milling was conducted in a semiautomatic vertical milling machine under 300rpm spindle speed, $200 \mathrm{~mm} / \mathrm{min}$ feed speed and $0.2 \mathrm{~mm}$ depth of cut increments. To obtain flat test surfaces the total depth of cut varied from 1 to $2 \mathrm{~mm}$.

Two similar sets of specimens were prepared, each composed of two groups, one corresponding to the asmachined surfaces, identified as cold work deformed surface (CWHS). The other, denominated undeformed polished surface (UPS), was further ground and polished to remove the deformed layer caused by the machining. Each set was composed of one UPS and two CWHS specimens (CWHS 1 and CWHS 2). The CWHS 2 specimens were used for 
Table 1: PTA hardfacing parameters used to process the coatings on AISI 304 substrates

\begin{tabular}{lcccccc}
\hline Current (A) & $\begin{array}{c}\text { Welding speed } \\
\left(\mathrm{cm} . \mathrm{min}^{-1}\right)\end{array}$ & $\begin{array}{c}\text { Powder feed } \\
\text { Rate }\left(\mathrm{kg} \cdot \mathrm{h}^{-1}\right)\end{array}$ & $\begin{array}{c}\text { Interbead } \\
\text { spacing }(\mathrm{mm})\end{array}$ & \multicolumn{3}{c}{ Gas type and flow rate $\left(\mathrm{L} \cdot \mathrm{min}^{-1}\right)$} \\
\hline 160 & 10 & 1,2 & $7 \pm 1$ & Argon, 2 & Argon, 2 & Argon, 12 \\
$\begin{array}{l}\text { Torch stand-off } \\
\text { distance }(\mathrm{mm})\end{array}$ & $\begin{array}{c}\text { Interpass } \\
\text { temperature }\left({ }^{\circ} \mathrm{C}\right)\end{array}$ & $\begin{array}{c}\text { Constritor } \\
\text { orifice diameter } \\
(\mathrm{mm})\end{array}$ & $\begin{array}{c}\text { Powder feeding } \\
\text { angle }\left({ }^{\circ}\right)\end{array}$ & Setback $(\mathrm{mm})$ & Grind Angle $\left({ }^{\circ}\right)$ & Diameter $(\mathrm{mm})$ \\
12 & $<200$ & 4,5 & 45 & 3 & $\sim 60$ & 4,8 \\
\hline
\end{tabular}

cavitation resistance characterization only, to improve results reliability and to access the experimental procedures repeatability. Top surface and cross-section of UPS and CWHS 1 specimens from both groups were prepared using standard metallographic procedures with silicon carbides abrasive paper down to 1200 mesh followed by polishing down to $0.3 \mu \mathrm{m}$ alumina. Etching by immersion in Marble reagent for up to three seconds allowed to examine the surface and cross-section under light microscope for the presence of slip lines traces, typically present in cold worked microstructures. The thickness of the cold work deformed layers was measured under light microscope with the aid of image analysis software.

Microhardness profiles are an average of three profiles with indentations every $0.25 \mathrm{~mm}$, up to $50 \mu \mathrm{m}$ from the top surface, Figure 2. To calculate the average hardness of the cross-section, substrate measurements were discarded. So were the outliers, identified with the aid of box plot graphs, considering a coefficient of 0.5 .

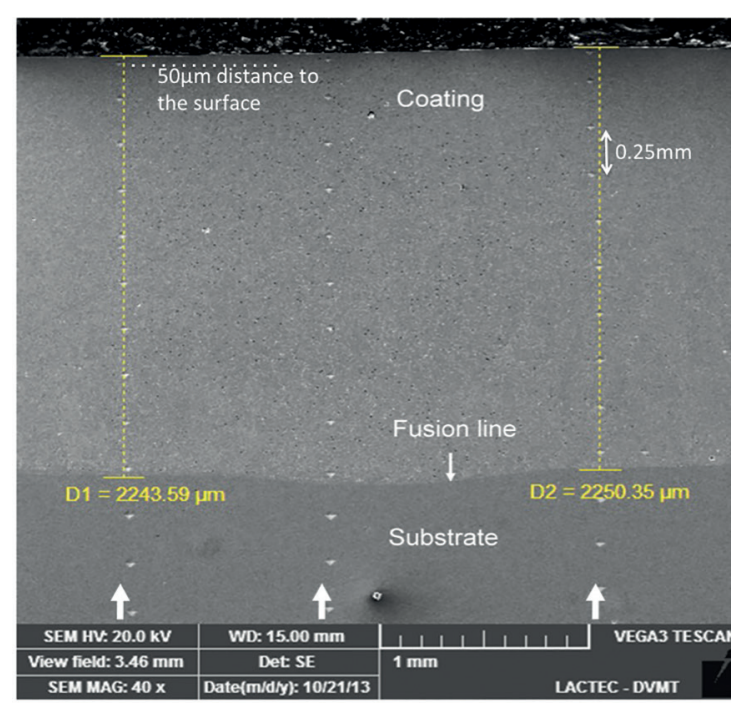

Figure 2: Cross-section of coating. Arrows indicate the rows of microhardness measurements and the fusion line

Vickers microhardness measurements under a $0.3 \mathrm{kgf}$ load were also carried out at the surface of UPS and CWHS 1 specimens. Surface hardness as an average of at least 10 measurements was determined. In order to guarantee that the hardness measurements refer to the deformed layer only, the depth of Vickers hardness indentation was calculated by trigonometry as being the height of a square based pyramid. Vickers hardness $H V$ is the ratio between the applied force $F$ (kgf) and the area of impression $A\left(\mathrm{~mm}^{2}\right)$, equation 1 . The latter is dependent on the average diagonal of the base $d_{a}(\mathrm{~mm})$ equation 2 . By replacing equation 2 in equation 1 and solving for $d_{a}$, it is possible to calculate the average diagonal as a function of Vickers hardness and the force applied (equation 3). As the angles formed between the edges of the Vickers pyramid are of $148^{\circ}{ }^{17}$ (Figure 3), the depth of the Vickers indentation may be expressed by simple trigonometry relation, as shown on equation 4 .

$$
\begin{gathered}
H V=\frac{F}{A} \\
A=\frac{d_{\mathrm{a}}^{2}}{2 \operatorname{sen} \frac{136^{\circ}}{2}}=\frac{d_{\mathrm{a}}^{2}}{1,854368} \\
d_{a}^{2}=\frac{F \cdot 1,854368}{H V} \\
d p=\frac{0,5 d_{a}}{\tan \left(\frac{148^{\circ}}{2}\right)}
\end{gathered}
$$

Ultrasonic vibratory cavitation erosion tests were performed by the stationary method with test conditions in conformance to ASTM G32-10: deionized water at $25 \pm 2^{\circ} \mathrm{C}$, test specimen at an immersion depth of $15 \mathrm{~mm}$, peak-to-peak displacement amplitude of $48 \mu \mathrm{m}$ and standoff distance of $500 \pm 10 \mu \mathrm{m}$. The tip of the horn used, Figure 4, differs from the standard and holds a total area of $2.75 \mathrm{~cm}^{2}$. Specimens were exposed to cavitation erosion up to $48 \mathrm{hs}$. The variation of erosion rate with cavitation time was determined by numerical differentiation (calculated by averaging the slopes of two adjacent points), using OriginLab software. To clearly display data tendency, a linear fit was added to data in the maximum rate period, as well as a $2^{\text {nd }}$ order polynomial fit to the acceleration period and a $4^{\text {th }}$ or $5^{\text {th }}$ order polynomial fit to the erosion rate versus cavitation time curve. The maximum erosion rate will be presented per unit of area to facilitate the comparison with literature results. 


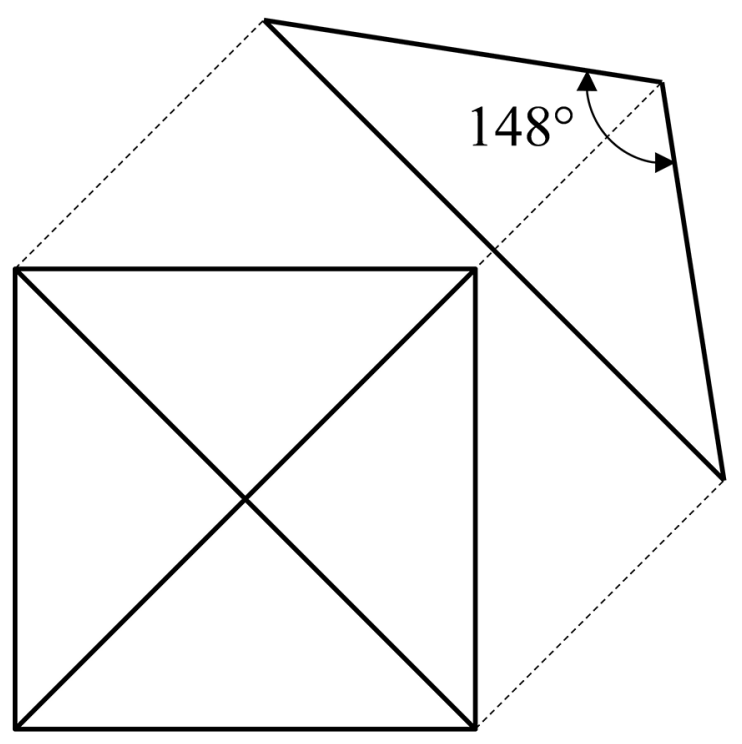

Figure 3: Angle between edges of Vickers indenter ${ }^{17}$.

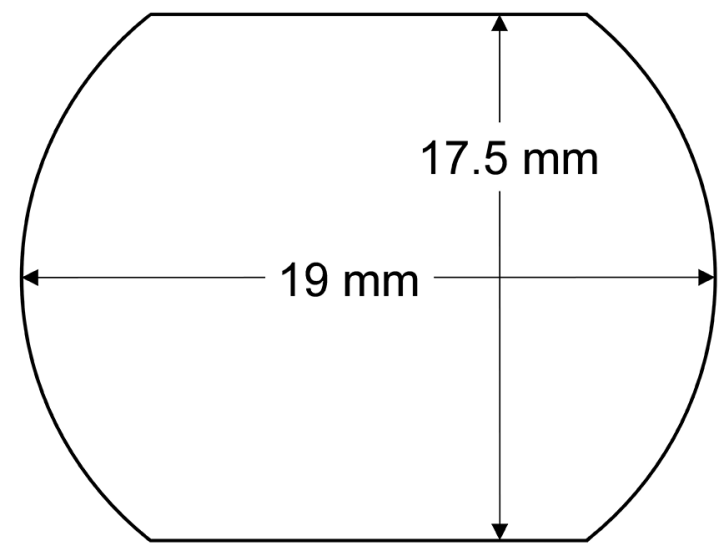

Figure 4: Geometry of the horn tip.

The hypothesis that the end of acceleration period in the CWHS specimens is marked by the complete removal of the hardened layer is raised and assessed. For that purpose, the mean depth of erosion at the end of the acceleration period is compared with the cold worked layer thickness. The mean depth of erosion $M D E$ was calculated as described in ASTM G32-10, considering a stainless steel density $d_{s}$ of $7.80 \mathrm{~g} . \mathrm{cm}^{-3}$, a cavitation area $A_{c}$ of $2.75 \mathrm{~cm}^{2}$ and mass losses $m$ (at the end of the acceleration period) of 3.4 and $2.53 \mathrm{mg}$, respectively, for the CWHS specimens, equation 5.

$$
M D E=\frac{m}{d_{s} A_{c}}
$$

\section{Results and Discussions}

\subsection{Surface starting condition}

Differences between the surface finishing of the two groups of specimens were assessed by light microscopy examination (Figure 5). The analysis revealed the presence of slip lines at the surface and transversal section of CWHS specimens, as expected following cold work deformation.

Vickers microhardness profile on the cross-section of CWHS specimens, Figure 6, shows a hardness increase towards the surface, associated with the surface deformation. The box plot graph of the cross-section microhardness, used to identify the outliers and to calculate the average microhardness of the undeformed cross-section, is shown in Figure 7.

Vickers microhardness of UPS and CWHS specimens, measured at the top surface and cross-section of coatings (as an average of cross section measurements, excluding the outliers), Figure 8, also illustrate the effect of cold work deformation. CWHS specimens exhibited a higher surface hardness, when compared to that measured at cross-section of coatings. The undeformed condition of UPS specimens resulted on a surface hardness closer to that measured at the cross-section, unaffected by the hardening at the surface. Assessing the penetration depth of the microhardness indentation confirms that microhardness at the surface of coatings is a reliable measure of the hardening caused by cold work. As observed and measured with an image analysis software, cold work affected a thickness of $\sim 100 \mu \mathrm{m}$ (Figure $5 \mathrm{c}$ ), whereas the depth of Vickers hardness indentation (equation 4) on the surface of CWHS specimens is limited to a maximum of $5.35 \mu \mathrm{m}$.

The higher hardness and the presence of slip lines on CWHS specimens endorse the cold work hardening of the coatings. On the other hand, the similar hardness of UPS surfaces and cross-section of coatings together with the absence of slip lines corroborate the undeformed state of UPS coatings. Therefore, it is accepted that subsequent testing of these surfaces can contribute to the understanding of the effect of deformed structures by cold work on the cavitation behavior.

\subsection{Cavitation erosion behavior}

Cavitation erosion behavior assessed by the variation of the cumulative mass loss and erosion rate with cavitation time is shown in Figure 9 (Set 1) and 10 (Set 2). Specimens CWHS 1 and 2 are represented in different graphs, (a) and (b), to avoid superposition of data and keep legibility. As a base for comparison, UPS data of graph (a) is repeated in graph (b). The erosion rate versus time curve for UPS, CWHS 1 and CWHS 2 specimens is presented in graphs (c), (d) and (e). To allow direct comparison of CWHS specimens, the maximum rate periods of all three specimens are represented in figure (f), along with the linear fit equations used in the nominal incubation period and maximum erosion rate calculation, Table 2 . 


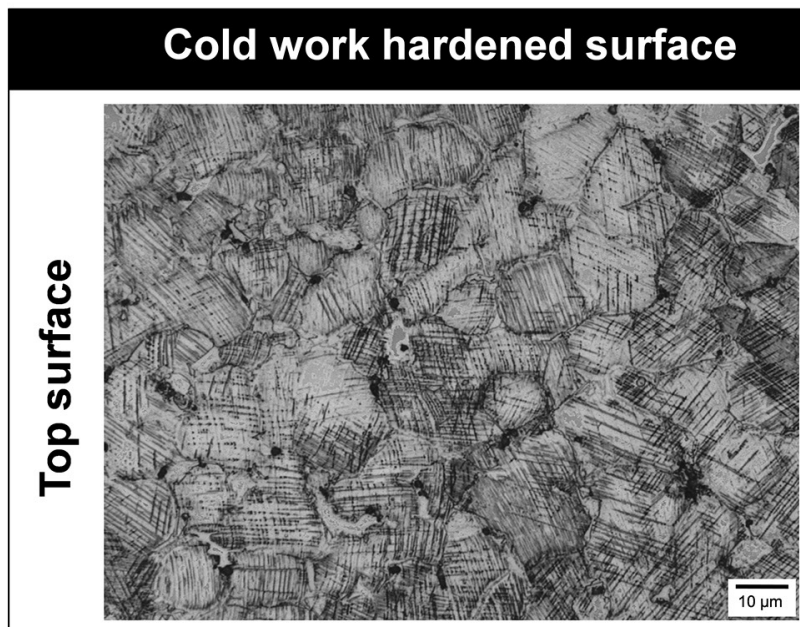

(a)

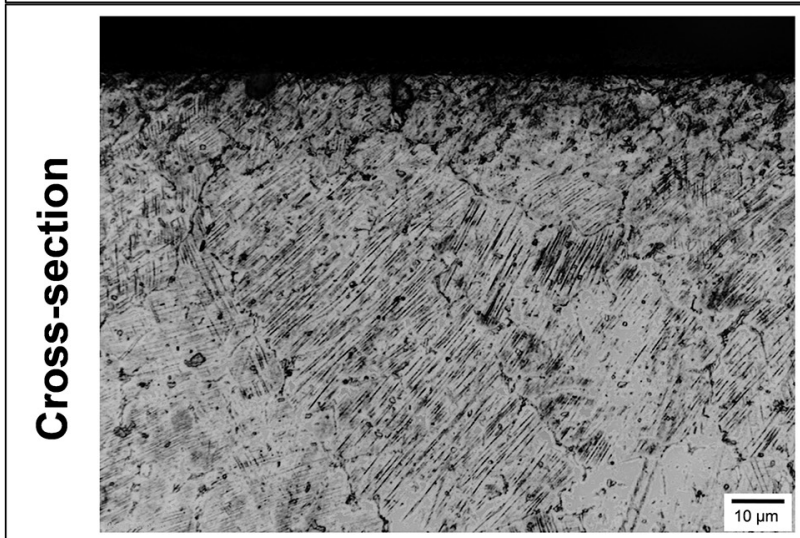

(c)

\section{Undeformed polished surface}

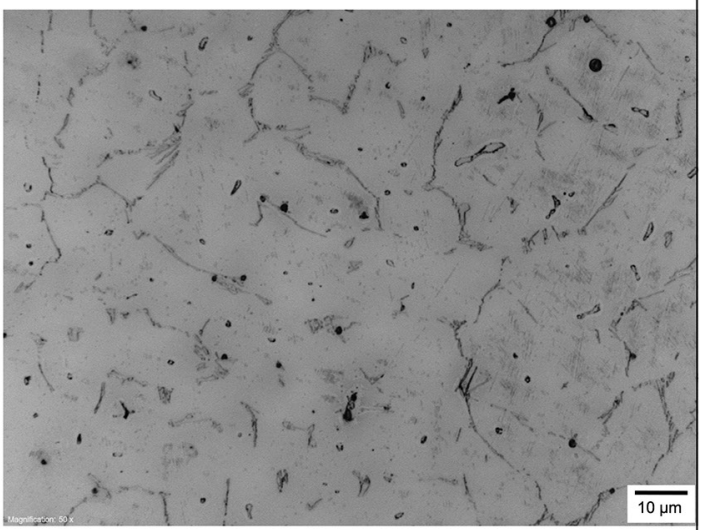

(b)

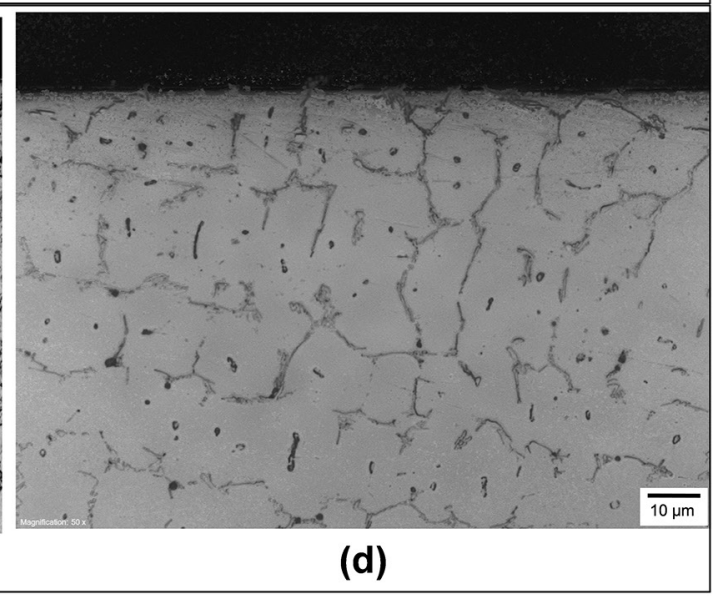

(d)

Figure 5: Presence of slip lines on top and cross-section of CWHS specimen, Fig. 5a and 5c, in contrast with its absence on the UPS specimen, Fig. $5 \mathrm{~b}$ and $5 \mathrm{~d}$
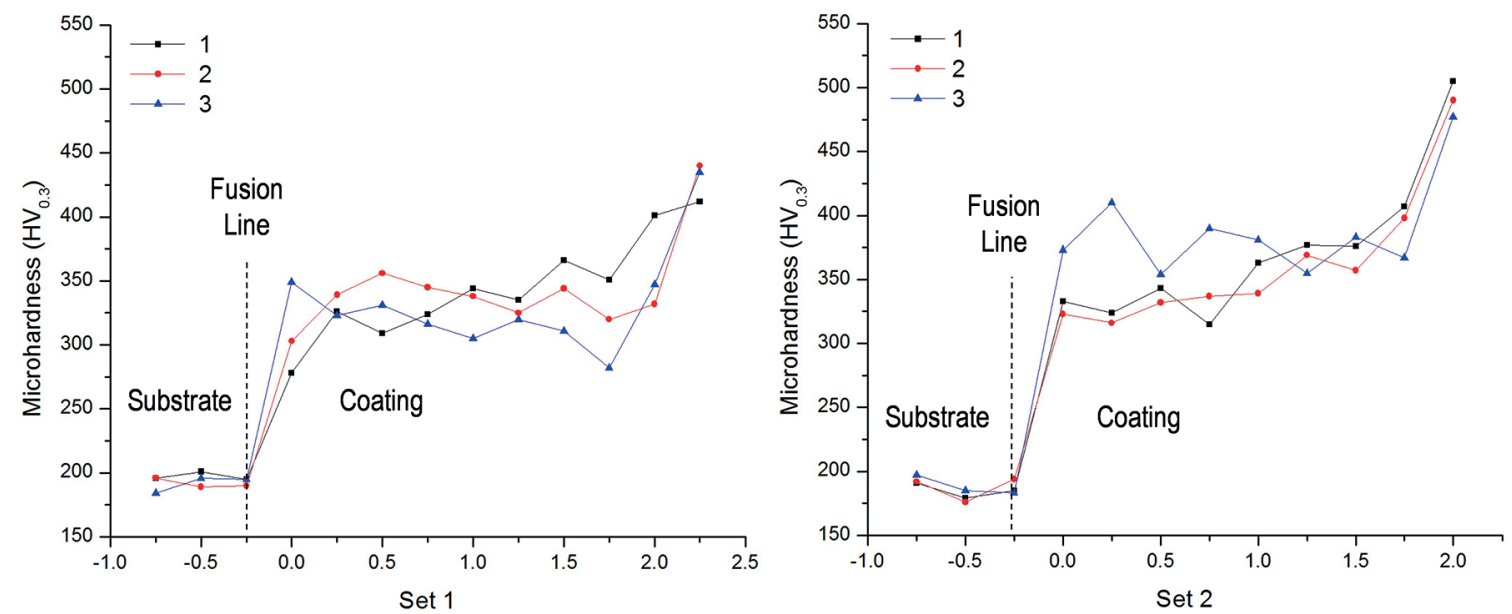

Figure 6: Vickers microhardness profile on the cross-section of CWHS specimens, showing a hardness increase towards the surface.

Results on Table 2 show that the nominal incubation time increases on deformed surfaces, in other words that the onset of the maximum erosion rate is delayed. Cold work deformation also contributed to a reduction in the maximum erosion rate, which is in accordance with the literature ${ }^{11}, 12$. The cold-work hardening decreased the 


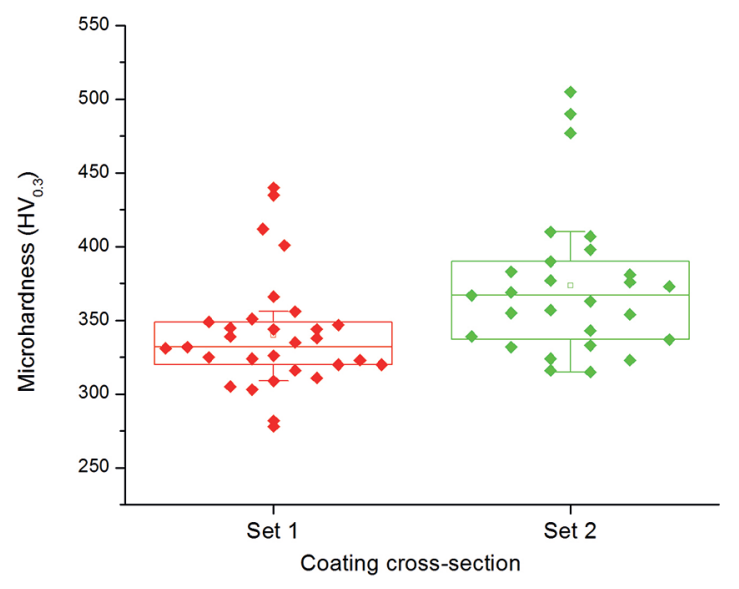

Figure 7: Indication of outliers in the cross-section microhardness of CWHS samples

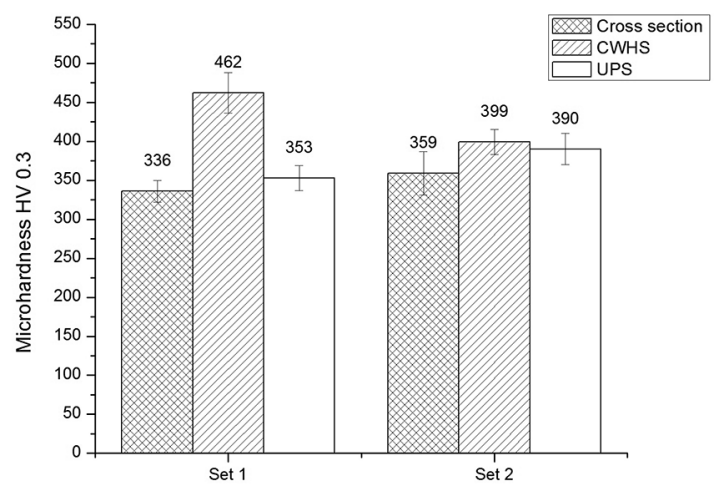

Figure 8: Vickers microhardness measured at the surface of UPS and CWHS specimens and at the cross-section, unaffected by the cold work hardening at the surface

maximum erosion rate for sets $1(\sim 32 \%)$ and $2(\sim 37 \%)$. Although this improvement in cavitation resistance is expressive, cold-work hardening was reported to reduce the maximum erosion rate of a UNS S31803 austenitic stainless steel in $80 \%{ }^{11}$. It is worth noting that the similar performances of specimens CWHS 1 and 2, in each set (Table 2), indicate a satisfying repeatability of the experimental procedures adopted.

Cavitation resistance can be said to increase because cold work deformation delays the onset of the maximum erosion rate and reduces its value. However, considering the incubation stage a slight reduction on cavitation resistance of CWHS specimens can be identified Figure 9(a) and 10(a). In both sets, the advent of mass loss starts earlier in CWHS 1 than in UPS specimens (6 and 12hs for CWHS 1 specimens of set 1 and 2, as opposed to 10 and $16 \mathrm{hs}$ for the respective UPS specimens). Both these findings remain in accordance with the literature that states an enhanced performance as the establishment of the maximum erosion rate is postponed, but also with the hypothesis of the negative effect of deformation previous to cavitation erosion that compromises the incubation time. These conflicting observations require further evaluation of the measured cavitation erosion. Detailed analyses of Figure 9 and 10 show that the main impact of the initially deformed structures is on the transitory stage between the incubation period and the onset of maximum erosion rate, the acceleration period. Cold work surfaces exhibit a magnified acceleration period (approximately 14hs for UPS, 24hs for CWHS 1 and 20hs for CWHS 2 specimens, set 1 , and approximately 14 for UPS, 30hs for CWHS 1 and 24hs for CWHS 2 specimens, set 2). This stage is the key to assess the effect of cold work hardening on the cavitation behavior. As mentioned before the boundaries between each stage are scatter and the acceleration period might end-up being incorporated into the nominal incubation time or in maximum erosion rate. If initial mass loss during the acceleration period is considered negligible, it can easily be incorporated in the incubation period that will be assumed to have increased. On the other hand, if part of the acceleration period is incorporated to the maximum-rate period, results can indicate a false reduction in the erosion rate. Therefore, it can be shown that deformation of surfaces previous to cavitation erosion, as those caused by machining, result on an enhanced cavitation erosion behavior associated with the expansion of the acceleration period and the delay of the onset of the maximum erosion rate.

Results might suggest that the end of the acceleration period, when the onset of the maximum erosion rate is identified, is related to the removal of the cold work layer. In as much, it is important to correlate the erosion depth measured after the acceleration period and the thickness of the cold work deformed layer as identified on the transverse cross-section of coatings. The mean depth of erosion measured at the end of the acceleration period is approximately of 1.6 and $1.2 \mu \mathrm{m}$ for sets 1 and 2 , respectively. These measurements are almost an order of magnitude lower than the total thickness of the cold worked hardened layer, indicating that the end of the acceleration period is not associated with the complete removal of the deformed layer. A better understanding is gained if one considers the events taking place during the acceleration period that culminate on the maximum erosion rate. In the acceleration period the effect of erosion mechanisms accounting for mass loss is less relevant than the accommodation of the deformation induced by shock waves that impact on the surface. As the test proceeds, the erosion mechanism becomes more important until that, at the end of the acceleration period, a balance between strain hardening mechanisms and the operating erosion mechanism during cavitation is achieved. This balance accounts for the constant erosion rate that characterizes the maximum erosion rate in Figure 9 and 10.

Regarding the raised hypothesis to the effect of cold work deformation on cavitation resistance and to the 

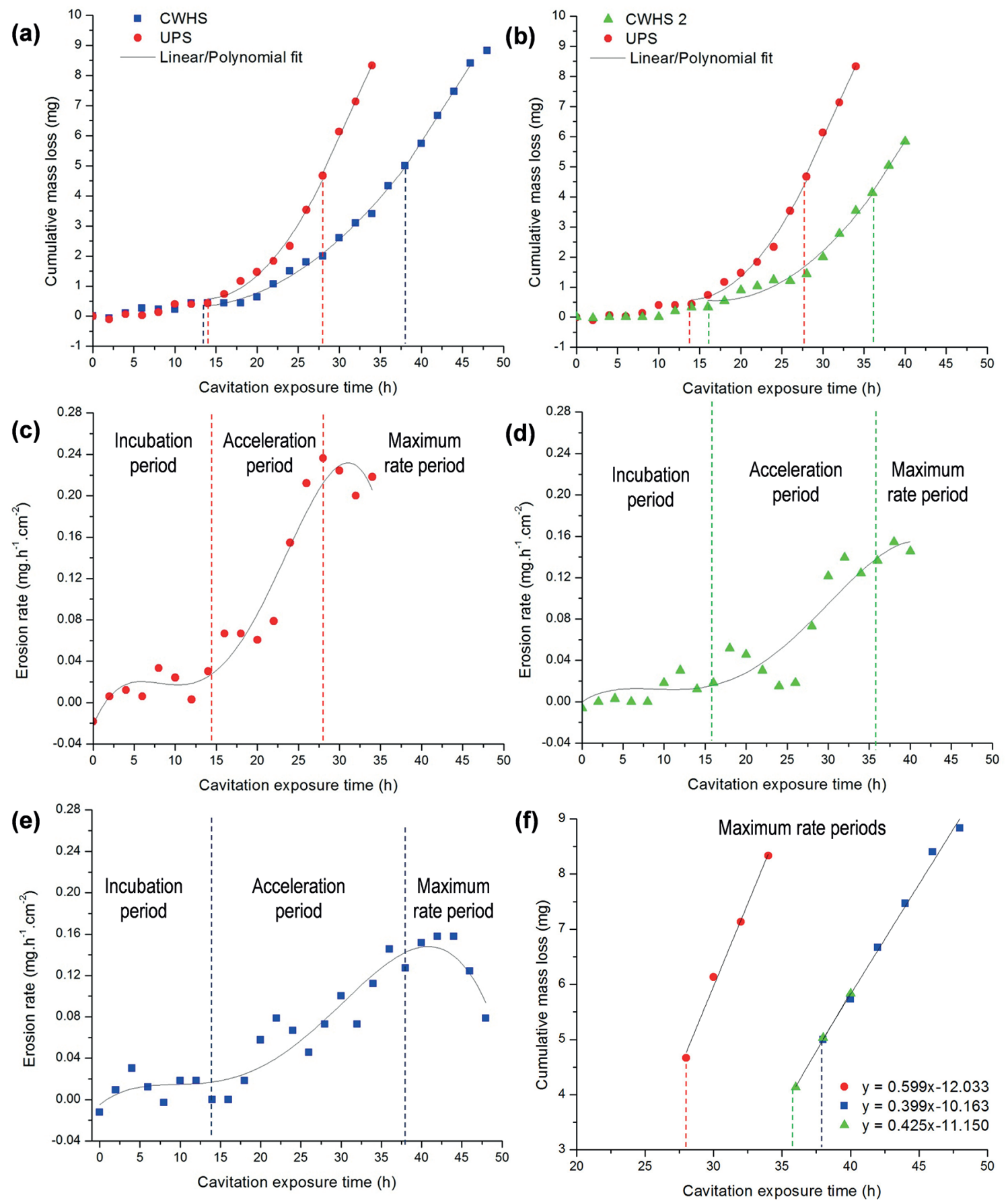

Figure 9: Cumulative mass loss and erosion rate over cavitation time for UPS, CWHS 1 and CWHS 2 specimens of Set 1. Extension of the acceleration period induced by the cold work hardening effect

complete removal of the cold work deformed layer being the trigger to the onset of maximum erosion rate, it is possible to state that:

Cavitation resistance is enhanced because cold work deformation magnified the acceleration period, a transition stage between the incubation period and maximum erosion rate;

The maximum erosion rate is reached as a balance between strain hardening and acting erosion mechanisms is established, event that is not related to the removal of the cold work deformed structure.

\section{Conclusions}

Under the conditions tested in this study, regarding the deformed structure produced by machining (cold work) on the cavitation erosion behavior of a FeCrMnSiB stainless steel coating, it is possible to conclude that: 

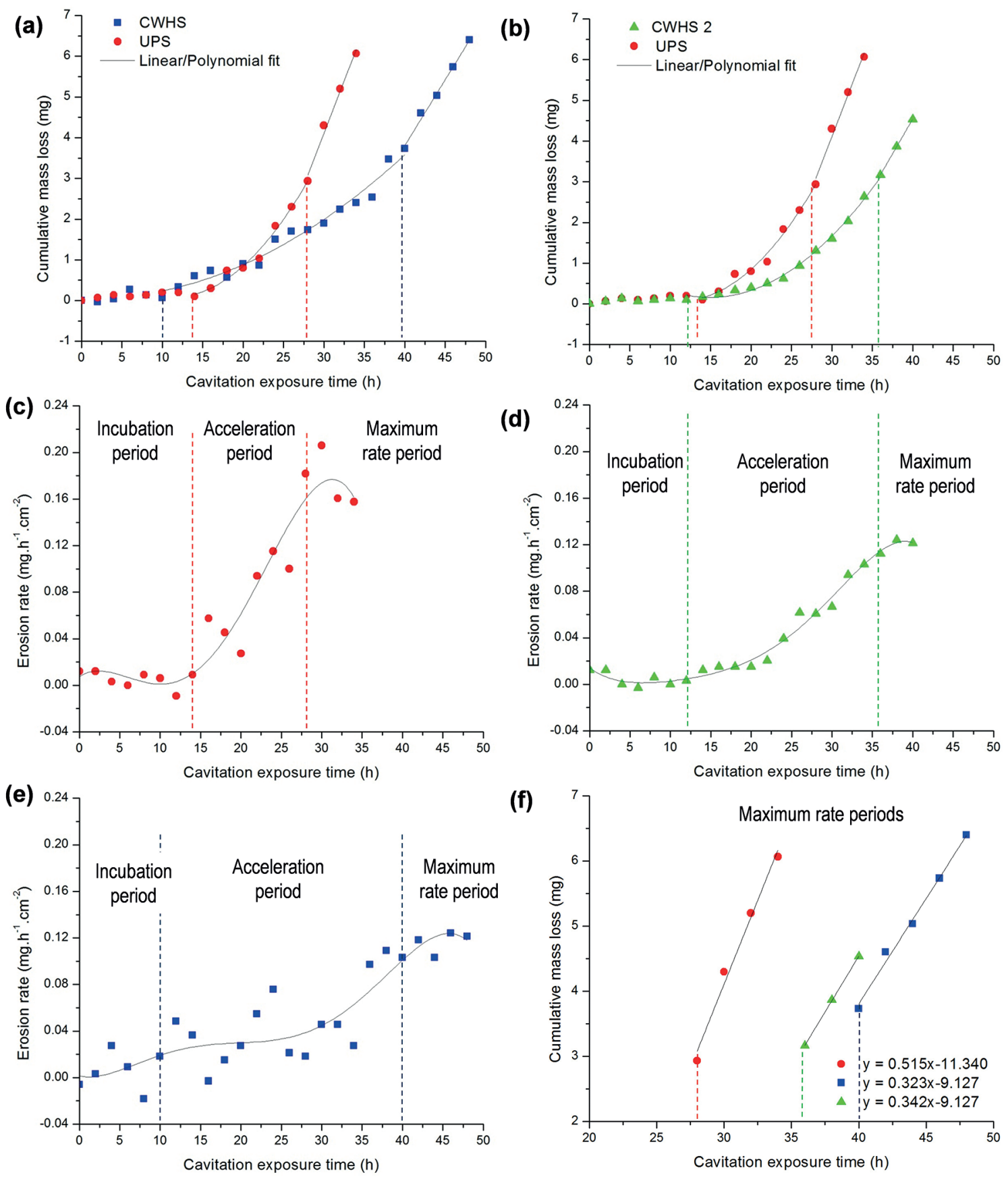

(f)

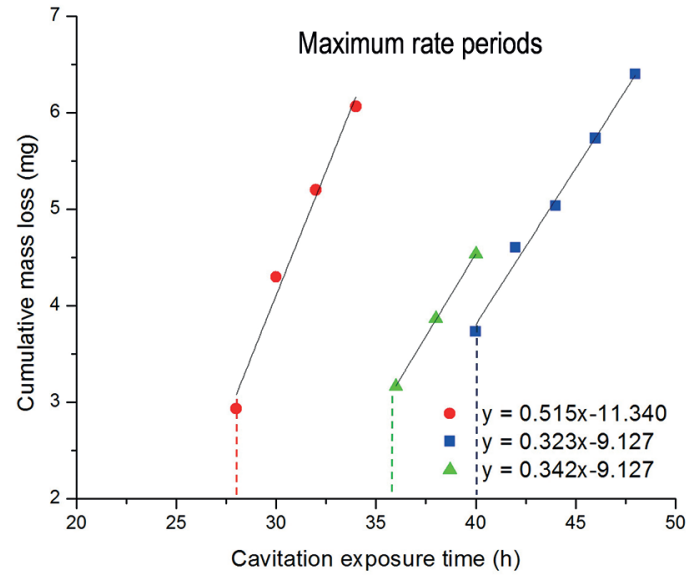

Figure 10: Cumulative mass loss and erosion rate over cavitation time for UPS, CWHS 1 and CWHS 2 specimens of Set 2. Extension of the acceleration period induced by the cold work hardening effect.

- The deformed structure produced by machining magnified the acceleration period during cavitation erosion, increasing the resistance to cavitation of the surface.

- Cold work deformation anticipated the onset of mass loss during cavitation.

- Cold work deformation postponed the onset of the maximum erosion rate and indirectly increased the nominal incubation time.
- Cold work deformation reduced the maximum erosion rate during cavitation.

- The end of acceleration period in cold work deformed surfaces is not marked by the complete removal of the deformed microstructure layer.

\section{Acknowledgements}

The authors would like to thank the ANEEL R\&D program, Copel and Institutos Lactec for providing financial 
Table 2: Nominal incubation time and maximum erosion rate per area.

\begin{tabular}{cccc}
\hline Specimen & $\begin{array}{c}\text { Nominal } \\
\text { incubation time }(\mathrm{h})\end{array}$ & $\begin{array}{c}\text { Maximum rate per } \\
\text { area }\left(\mathrm{mg} \cdot \mathrm{h}^{-1} \cdot \mathrm{cm}^{-2}\right)\end{array}$ \\
\hline \multirow{3}{*}{ Set 1 } & CWHS & 20.1 & 0.22 \\
& CWHS 1 & 25.5 & 0.15 \\
& UPS & 26.2 & 0.15 \\
Set 2 & CWHS 1 & 22.0 & 0.19 \\
& CWHS 2 & 28.3 & 0.12 \\
& & 26.7 & 0.12 \\
\hline
\end{tabular}

support for this project. Special thanks go to Leandro João da Silva, M.Eng, for helpful discussions.

\section{References}

1. Brennen CE. Cavitation Bubble Collapse. In: Brennen CE. Cavitation and Bubble Dynamics. New York: Oxford University Press; 1995. p. 79-112.

2. Duncan W Jr. Turbine Repair. In: Facilities Instructions, Standards \& Techniques. Denver: United States Department of the Interior - Bureau of Reclamation; 1989. p. 1-65.

3. Steel Founders' Society of America. Supplement 8 High Alloy Data Sheets Corrosion series. Steel Casting Handbook; 2004. p. 1-93. [Cited 2015 Jun 10]. Available from: www.sfsa.org/ sfsa/pubs/hbk/s8.pdf

4. Materials for Propeller Fabrication. Rules for Classification and Construction: Materials and Welding. Hamburg: Germanischer Lloyd Aktiengesellschaft; 2009. p. 1-30. [Cited 2015 Jun 10]. Available from: http://www.gl-group.com/infoServices/rules/ pdfs/gl_ii-1-5_e.pdf

5. Morrow SJ. Materials Selection for Seawater Pumps. In: Proceedings of the Twenty-Sixth International Pump Users Symposium; 2010. p. 73-80. [Cited 2016 Jul 19]. Available from: http://turbolab. tamu.edu/proc/pumpproc/p26/ch09_Morrow.pdf

6. Francis R. Pumps and Valves. In: Guides to Good Practice in Corrosion Control. National Physics Laboratory; 2000. p. 1-11. [Cited 2015 Jun 10]. Available from: http://www.npl.co.uk/ upload/pdf/pumps.pdf
7. Niederhofer P, Huth S. Cavitation erosion resistance of high interstitial CrMnCN austenitic stainless steels. Wear. 2013;301(12):457-466

8. Kim JH, Na KS, Kim GG, Yoon CS, Kim SJ. Effect of manganese on the cavitation erosion resistance of iron-chromium-carbonsilicon alloys for replacing cobalt-base Stellite. Journal of Nuclear Materials. 2006;352(1-3):85-89.

9. Ribeiro HO, Buschinelli AJA, Dutra JC, D’Oliveira ASCM. Resistência à erosão por cavitação de aços inoxidáveis austeníticos CrMnSiN depositados por PTA. Soldagem \& Inspeção. 2010;15(2):121-129.

10. Cruz JR. Influência do boro na resistência à cavitação de revestimentos processados com pós atomizados e com misturas mecânicas de pós elementares de $\mathrm{Fe}-\mathrm{Cr}-\mathrm{Mn}$-Si-B. [Dissertação de Mestrado]. Curitiba. Universidade Federal do Paraná; 2014.

11. Mesa DH, Garzón CM, Tschiptschin AP. Influence of coldwork on the cavitation erosion resistance and on the damage mechanisms in high-nitrogen austenitic stainless steels. Wear. 2011;271(9-10):1372-1377.

12. Mills DJ, Knutsen RD. An Investigation of the tribological behaviour of a high-nitrogen $\mathrm{Cr}-\mathrm{Mn}$ austenitic stainless steel. Wear. 1998;215(1-2):83-90.

13. Santos JF, Garzón CM, Tschiptschin AP. Improvement of the cavitation erosion resistance of an AISI 304L austenitic stainless steel by high temperature gas nitriding. Materials Science and Engineering: A. 2004;382(1-2):378-386.

14. Santa JF, Blanco JA, Giraldo JE, Toro A. Cavitation erosion of martensitic and austenitic stainless steel welded coatings. Wear. 2011;271(9-10):1445-1453.

15. Xiaojun Z, Procopiak LAJ, Souza NC, D’Oliveira ASCM. Phase transformation during cavitation erosion of a Co stainless steel. Materials Science and Engineering: A. 2003;358(1-2):199-204.

16. Yabuki A, Noishiki K, Komori K, Matsumura M. The Surface Behavior of Metallic Materials During the Incubation Period of Cavitation Erosion. In: Totten GE, Wills DK, Feldmann DG, eds. Hydraulic Failure Analysis: Fluids, Components, and System Effects. ASTM STP 1339. West Conshohocken: American Society for Testings and Materials; 2001. p. 357-369.

17. Franco Júnior AR, Pintaúde G, Sinatora A, Pinedo EC, Tschiptschin AP. The use of a vickers indenter in depth sensing indentation for measuring elastic modulus and vickers hardness. Materials Research. 2004;7(3):483-491. 